\title{
Guidelines and best practice recommendations on reproductive health services provision amid COVID-19 pandemic: scoping review
}

\author{
Lemi Belay Tolu ${ }^{1 *}$ D, Garumma Tolu Feyissa ${ }^{2}$ and Wondimu Gudu Jeldu ${ }^{1}$
}

\begin{abstract}
Background: Policymakers and health professionals prefer to use summarized evidence of practice recommendations. The aim of this scoping review is therefore to identify available guidelines, consensus statements, the standard of practice, and practice recommendations on reproductive health service provision during the COVID-19 pandemics.

Methods: We searched guideline databases and websites of professional associations and international organizations working on sexual and reproductive health. We looked for practice recommendations on sexual reproductive health services (SRH) during COVID-19 pandemics. Additionally, we searched: MEDLINE, EMBASE, and Google Scholar. Data extraction was done by two independent reviewers using a customized tool that was developed to record the key information of the source that's relevant to the review question. The difference between the two authors on data extraction was resolved by discussion.

Results: A total of 21 records were included in the review. Identified recommendations were classified into thematic areas. The records addressed approaches to antenatal care, labour and delivery, postnatal care, safe abortion, contraception, gender-based violence, and artificial reproduction.

Conclusions: There were consistent consensus statements and recommendations that there should be access to sexual and reproductive health services like antenatal care (ANC), postnatal care (PNC), contraception service, safe abortion care, and clinical management of rape survivors during the COVID-19 pandemics with the concerted effort of service re-organization. The practice recommendations focus on innovative ways of service provision to minimize patient and staff exposure to COVID-19 as well as alleviate the burden on the health care system. These include utilizing telemedicine and community/home-based care or self-care.
\end{abstract}

Keywords: COVID-19, Pandemics, Reproductive health, Antenatal care, Labor/delivery, Postnatal care, Abortion, Contraception, SARS-CoV-2

\footnotetext{
* Correspondence: lemi.belay@gmail.com

'Department of Obstetrics and Gynecology, Saint Paul's Hospital Millennium Medical College, Addis Ababa, Ethiopia

Full list of author information is available at the end of the article
}

C C The Author(s). 2021 Open Access This article is licensed under a Creative Commons Attribution 4.0 International License, which permits use, sharing, adaptation, distribution and reproduction in any medium or format, as long as you give appropriate credit to the original author(s) and the source, provide a link to the Creative Commons licence, and indicate if changes were made. The images or other third party material in this article are included in the article's Creative Commons licence, unless indicated otherwise in a credit line to the material. If material is not included in the article's Creative Commons licence and your intended use is not permitted by statutory regulation or exceeds the permitted use, you will need to obtain permission directly from the copyright holder. To view a copy of this licence, visit http://creativecommons.org/licenses/by/4.0/. The Creative Commons Public Domain Dedication waiver (http://creativecommons.org/publicdomain/zero/1.0/) applies to the data made available in this article, unless otherwise stated in a credit line to the data. 


\section{Background}

The 2019-20 coronavirus pandemic is an ongoing pandemic of coronavirus disease 2019 (COVID-19), caused by severe acute respiratory syndrome coronavirus 2 (SARS-CoV-2) [1]. The outbreak was first identified in Wuhan, Hubei Province, China, in December 2019. The World Health Organization (WHO) declared the outbreak to be a Public Health Emergency of International Concern on 30 January 2020 and recognized it as a pandemic on 11 March 2020 [2, 3].

The WHO considered reproductive health services, including care during pregnancy and child breath as an essential health service to continue during the COVID-19 pandemics [4]. Additionally, WHO Stated, "Women's choices and rights to sexual and reproductive health care should be respected irrespective of COVID-19 status, including access to contraception and safe abortion to the full extent of the law" [5]. But when staff and services are under extreme stress there is a real risk of increasing avoidable harm. The tremendous burden caused by the COVID-19 outbreak is exceeding the capacity of many national and local health systems which is jeopardizing routine service delivery and undermining other health priorities. Furthermore, there might be reduced healthcare-seeking behavior among patients because of fear and anxiety of contracting COVID-19 [6, 7] As such the evolving COVID-19 pandemic may affect routine services including sexual, reproductive, and maternal health services delivery. Marie Stopes International (MSI) warned near 9.5 million people will miss out on reproductive service if service reduction continues for 3 months because of the lockdown [8]. Experience in past epidemics also has shown that lack of access to essential health services and shut down of services unrelated to the epidemic response resulted in more deaths than the epidemic itself [9].

The aim of this scoping review is therefore to identify available guidelines, consensus statements, the standard of practice, and practice recommendations on reproductive health service provision during the COVID-19 pandemic.

\section{Hypothesis}

- What's is the reproductive health service practice approach during the current COVID-19 pandemic?

- What are the available recommendations on service re-organization of reproductive health services amid COVID-19 pandemics?

\section{Methods and materials}

\section{Types of source and search strategy}

We followed three steps in locating relevant records. First, we searched for professional associations and international organization's guidelines, protocols, consensus statements, and practice recommendations on sexual reproductive health services (SRH) during COVID-19 pandemics. Second, we searched for guideline databases using text words.

The association and organization selected were based on input from authors and consultations from 23 expertise in different areas of reproductive health and snowball technique applied to make the search as comprehensive as possible. To identify reproductive health experts, we did a limited search on MEDLINE to identify authors of papers published on reproductive health. We used email to reach identified authors for the survey. Finally, we developed a search strategy to look at any relevant emerging practice recommendations missed on the website and guideline database search or not endorsed by associations and organizations. We searched the following databases: MEDLINE, EMBASE, and Google Scholar. The reference lists of all included records were screened for additional studies. Text words and Mesh terms were used to develop the search strategy (Table 2 in Appendix 1, Search strategy). Electronic search and screening of records against inclusion criteria were done by two independent individuals between April 1 to April 30, 2020.

\section{Inclusion criteria}

The report included in this scoping review was prepared based on the JBI manual of the scoping review framework [10]. We considered the following inclusion criteria:

\section{Population}

This review considered adolescent girls, reproductiveage women, pregnant women, women seeking abortion services, health care providers, health managers, and health care institutions.

\section{Concept}

The review considered records addressing service delivery approaches and recommendations on Antenatal care (ANC), labour and delivery, postnatal care (PNC), contraceptive service, safe abortion service, management of rape survivors, and Assisted reproductive technology (ART) services during the COVID-19 pandemic.

\section{Context}

The review considered worldwide documents/records addressing antenatal care (ANC), labour and delivery, postnatal care (PNC), contraceptive service, safe abortion service, clinical management of rape survivors, and Assisted reproductive technology (ART) services during the COVID-19 pandemic. 


\section{Types of documents/records}

We included records labeled guidelines, or recommendations, or consensus, or practice parameters, or position papers on SRH service practice during the COVID19 pandemics. The search is limited to English and 1 year (considering the duration of the outbreak to be after December 2019).

\section{Data extraction and synthesis}

Data extraction was done by two independent persons using a validated tool that was developed to record the key information of the source that's relevant to the review question. The data extraction tool was developed for guideline related documents, consensus statements, and practice recommendations. Types of the document and summary of recommendations were extracted. The difference between the two authors on data extraction was resolved by discussion. Data were extracted for the following practice areas: antenatal care, labour and delivery, postnatal care, safe abortion care, contraception service, gender-based violence, and assisted reproduction (Supplementary material, S1 and S1 documents). We looked for service delivery organization changes, new position statements, and guidelines on these services areas concerning the COVID-19 pandemic. We categorized identified guidelines or practice recommendations according to service delivery thematic areas and the findings were described narratively.

\section{Results}

We reviewed 24 websites, four guideline databases, MEDLINE, EMBASE, and Google Scholar. The search yielded a total of 520 records. After removing duplicates, 380 documents were retained for further examination. After screening the titles and abstracts, 36 papers were retained for full-text review. Based on pre-defined inclusion criteria, 21 records were included in the scoping review (Fig. 1). Six of the included records had international scope while four, six, two, two, and one where America, Europe, Australia, Canada, and Africa based guidelines and practice recommendations.

\section{Characteristics of included records (guidelines and practice recommendations)}

Identified recommendations are categorized into service thematic areas: Antenatal Care (ANC), labour and delivery, Postnatal Care (PNC), abortion, contraception, safe abortion, gender-based violence, and assisted reproduction (Table 1).

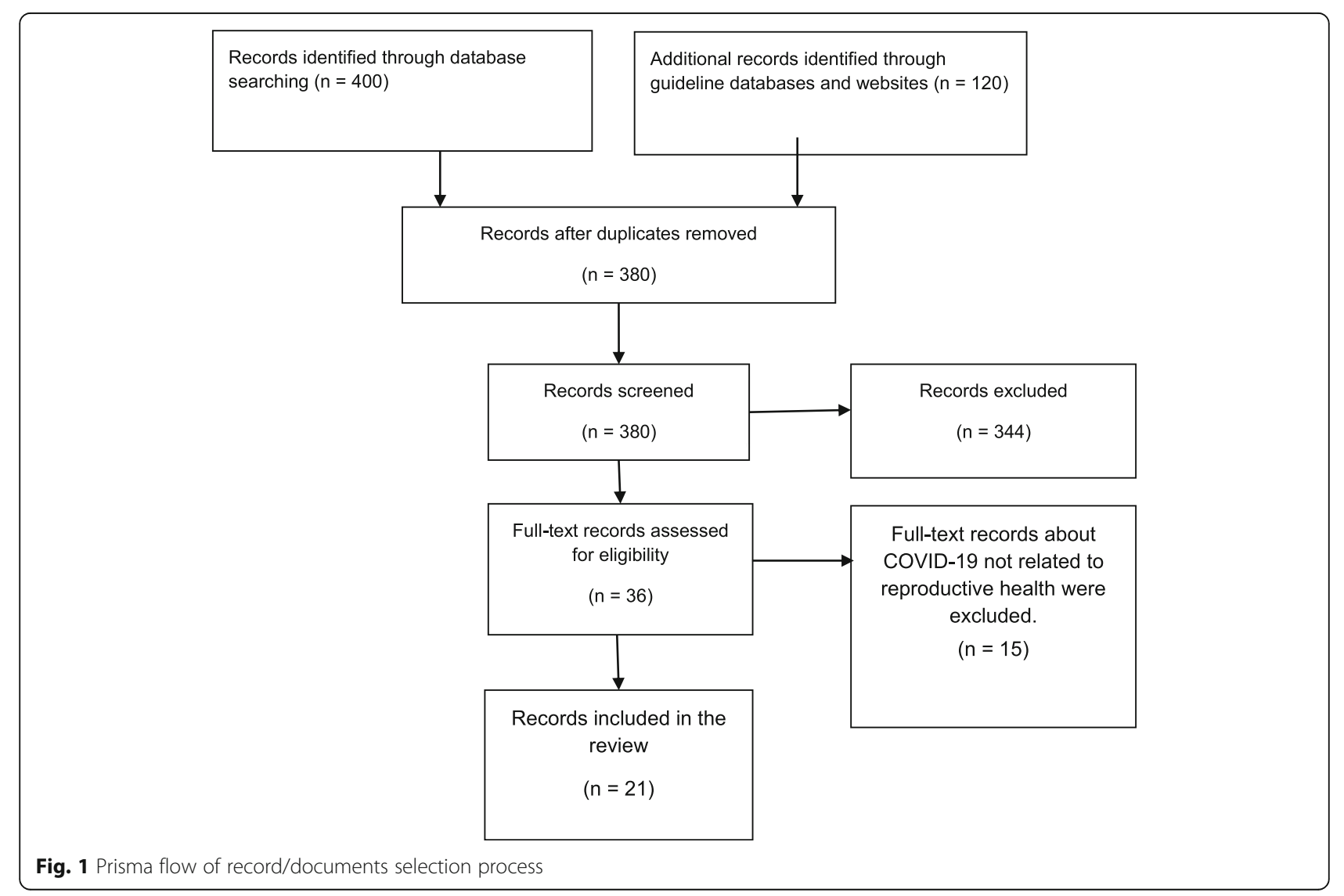


Table 1 Characteristics of identified records and common practice recommendations areas

\begin{tabular}{|c|c|c|c|c|}
\hline \multicolumn{2}{|c|}{$\begin{array}{l}\text { Practice area and common } \\
\text { recommendations }\end{array}$} & \multirow{2}{*}{\begin{tabular}{|l|}
$\begin{array}{l}\text { Number } \\
\text { of records }\end{array}$ \\
6
\end{tabular}} & \multirow{2}{*}{$\begin{array}{l}\text { Sources and name of the record } \\
\text { RCOG, ACOG, MFM Guidance, WHO, } \\
\text { SMFM, NHS }\end{array}$} & \multirow{2}{*}{$\begin{array}{l}\text { Types of the document } \\
\text { (guideline, commentaries, } \\
\text { position statements) } \\
\text { Guidelines, commentaires }\end{array}$} \\
\hline $\begin{array}{l}\text { Antenatal } \\
\text { care }\end{array}$ & Pre-triage (screening) at visit & & & \\
\hline & $\begin{array}{l}\text { Mode of service provision (telehealth, virtual, } \\
\text { home) }\end{array}$ & 7 & $\begin{array}{l}\text { FIGO, RCOG, ACOG, MFM Guidance, } \\
\text { WHO, SMFM, NHS }\end{array}$ & $\begin{array}{l}\text { Guidelines, position } \\
\text { statements commentaires }\end{array}$ \\
\hline & Schedule of visits & 3 & RCOG, SMFM, RCM & $\begin{array}{l}\text { Guidance \& position } \\
\text { statements }\end{array}$ \\
\hline & $\begin{array}{l}\text { Attendant with pregnant mother (limit/screen } \\
\text { status) }\end{array}$ & 3 & RCOG, FIGO, MFM guidance & Guidance \\
\hline \multirow[t]{2}{*}{$\begin{array}{l}\text { Labor and } \\
\text { delivery }\end{array}$} & $\begin{array}{l}\text { Place of birth (community/home/mid-wife led } \\
\text { freestanding units) }\end{array}$ & 4 & RCOG, ICM, NHS, RCM & $\begin{array}{l}\text { Guidance \& position } \\
\text { statements }\end{array}$ \\
\hline & Labor companion (allow/limit at labor wards) & 2 & NHS, MFM Guidance & $\begin{array}{l}\text { Guidance \& Position } \\
\text { statements }\end{array}$ \\
\hline \multirow{2}{*}{$\begin{array}{l}\text { Post-natal } \\
\text { care }\end{array}$} & Early Discharge & 1 & ACOG & Commentary \\
\hline & Post-natal visits (virtual/ home based) & 4 & ACOG, RCOG, ICM, WHO & Guidance, Commentary \\
\hline \multicolumn{2}{|c|}{ Obstetric Referral pathways (modifications/organization) } & 3 & RCOG, RCM, WHO & Guidance \\
\hline \multirow[t]{3}{*}{ Safe abortion } & No-touch /no-test early medication abortion. & 11 & $\begin{array}{l}\text { FIGO, RCM, SOGC, RCOG, RANZCOG, } \\
\text { NAF, IPPF, UNFPA, MSI, FSRH, BSACP }\end{array}$ & $\begin{array}{l}\text { Guidance, position } \\
\text { statements, and } \\
\text { commentaries. }\end{array}$ \\
\hline & $\begin{array}{l}\text { Minimum contact second-trimester medication } \\
\text { abortion. }\end{array}$ & 11 & $\begin{array}{l}\text { FIGO, RCM, SOGC, RCOG, RANZCOG, } \\
\text { NAF, IPPF, UNFPA, MSI, FSRH, BSACP }\end{array}$ & $\begin{array}{l}\text { Guidance, position } \\
\text { statements, and } \\
\text { commentaries }\end{array}$ \\
\hline & Minimum contact surgical abortion. & 11 & $\begin{array}{l}\text { FIGO, RCM, SOGC, RCOG, RANZCOG, } \\
\text { NAF, IPPF, UNFPA, MSI, FSRH, BSACP }\end{array}$ & $\begin{array}{l}\text { Guidance, position } \\
\text { statements, and } \\
\text { commentaries }\end{array}$ \\
\hline \multirow[t]{3}{*}{ Contraception } & Self-serving contraception methods. & 9 & $\begin{array}{l}\text { FIGO, WHO, RCM, RCOG, FSRH, IPPF, } \\
\text { UNFPA, MSI, RANZCOG }\end{array}$ & $\begin{array}{l}\text { Guidance, position } \\
\text { statements, and } \\
\text { commentaries }\end{array}$ \\
\hline & Extended use of long-term contraceptives & 7 & $\begin{array}{l}\text { RCM, RCOG, FSRH, IPPF, UNFPA, MSI, } \\
\text { RANZCOG }\end{array}$ & $\begin{array}{l}\text { Guidance, position } \\
\text { statements, and } \\
\text { commentaries }\end{array}$ \\
\hline & Minimum contact long term contraceptives. & 8 & $\begin{array}{l}\text { FIGO, RCM, RCOG, FSRH, IPPF, UNFPA, } \\
\text { MSI, RANZCOG }\end{array}$ & $\begin{array}{l}\text { Guidance, position } \\
\text { statements, and } \\
\text { commentaries }\end{array}$ \\
\hline $\begin{array}{l}\text { Gender-based } \\
\text { violence }\end{array}$ & $\begin{array}{l}\text { Medical, legal, and policy mechanisms for victims } \\
\text { should be in place. }\end{array}$ & 8 & $\begin{array}{l}\text { UNFPA, WHO, FIGO, RANZOG, RCOG, } \\
\text { RCM, FSRH and UN Women }\end{array}$ & Position statements \\
\hline $\begin{array}{l}\text { Assisted } \\
\text { reproduction }\end{array}$ & $\begin{array}{l}\text { No new cycle during pandemics except fertility } \\
\text { preservation and freeze all embryos. }\end{array}$ & 5 & $\begin{array}{l}\text { ESHRE, BFS, FSA, HFEA, SASREG and } \\
\text { ASRM }\end{array}$ & $\begin{array}{l}\text { Position statements and } \\
\text { commentaries. }\end{array}$ \\
\hline
\end{tabular}

\section{Antenatal care}

Antenatal care services are one of the essential services that the WHO recommends being given during pandemics [WHO]. One of the major focus areas of the guidelines and consensus statements is on antenatal care provision during the COVID-19 pandemic.

\section{Pre-triage for ANC}

In circumstances where a pregnant mother presents for a face to face care most of the societies including FIGO recommend screening (triage) at the entrance into the health facility [4, 11-15]. The MFM guidance advises on even an earlier pre-triage with phone communication while the patient is at home before she visits ANC clinics [MFM guidance]. Some even recommend screening of attendants too.

\section{Mode of ANC provision}

The mode of ANC services delivery should be modified, and innovative ways of care provision are recommended with due consideration of individualized care plan (in eight of the reviewed 12 documents) [4, 12-18]. In lowrisk mothers, telehealth (voice or video calls) is a viable option for delivering prenatal care as well as triaging women before they present to the clinic. Remote access options such as home antenatal service provision by community health care workers are also suggested in WHO, RCOG, and SMFM guidelines [4, 11, 14]. But 
face to face care provision is advised in high-risk pregnancies and women with emergency conditions where physical examination and other clinical/laboratory tests might be needed $[12,16]$.

\section{ANC schedules}

There is no clear recommendation in any of the guidelines and consensus statements regarding modifications in the timing of 1st visit, subsequent visits, and the total number of ANC visits. But omitting or virtual visits are recommended by the RCOG and RCM [11, 19], while standard schedules are advised in high-risk mothers by the SMFM [14]. The RCOG guidance on antenatal care services and ultrasound in the COVID-19 pandemic suggests that local practice should determine re-booking [11]. Repeat visits might be scheduled using telehealth. In three of the guidelines, it is suggested that pregnant mothers present for prenatal visits alone or just with a single screen-negative attendant $[11,12,15]$.

\section{The extent of prenatal care services}

There are no recommendations on modifications to the extent of service provision in the standard prenatal care. The only guideline addressing the issue is the RCOG labor, delivery, and postnatal guidance in the COVID-19 pandemic which states scans and antenatal appointments and other investigations should be provided within a single visit one-stop clinic [11].

\section{Obstetric referral pathways}

One of the health service challenges encountered during any pandemics is how to effectively sustain functional referral pathways, especially in low resource settings. The joint RCOG/RCM Guidance for provision of midwife-led settings and home birth in the evolving coronavirus (COVID-19) pandemic states there is good evidence to inform transport for complications and obstetric emergencies. Solutions are likely to be contextspecific, dependent on e.g. urban/rural context, and the extent of pressure on the ambulance services [19]. The RCOG guidance on labor/delivery and postnatal care states obstetric antenatal referrals can be triaged locally by a consultant with a telephone appointment to discuss a proposed plan of care with the woman [16]. It is advised by the WHO that instituting targeted referral and counter-referral criteria and processes are crucial to keeping the system from becoming overwhelmed by labour and delivery [4].

\section{Labor and delivery}

\section{Induction and elective cesarean delivery (CD)}

There is limited guidance on the induction of labor in the face of the COVID-19 pandemic. The RCOG recommends labor induction in low-risk mothers can be considered as an outpatient department (OPD) to ease the burden on inpatient services [16]. The NHS advises that elective procedures (including) be done as planned to avoid burden on emergency services [17].

\section{Place of delivery}

In institutional deliveries limiting the number of attendants is recommended but with due consideration of making sure that there is always a family member around in emergencies. A single preferably screen negative labor companion is recommended in 2 of the guidelines $[12,17]$.

The COVID-19 pandemic will strain labor and delivery services if tertiary centers are overwhelmed with the care of non-pregnant patients with COVID-19 infection. Some maternal health service providers might also be called to provide care in non-obstetric settings. There is also a concern for a healthy woman giving birth in a facility acquiring the COVID-19 infection. Hence, some of the guidelines have addressed the issue of the place of birth in the face of the COVID-19 pandemic. The International Confederation of Midwives (ICM) and the Royal College of Midwives (RCM) support community birth (home birth) for healthy women and newborn infants if there are appropriate mid-wife staffing and referrals are facilitated in obstetric emergencies [19-21]. Where these are not available, it may be necessary to modify available services, seeking at all times to maximize the provision of a safe and positive birth experience to all women [21]. The NHS Clinical guide for the temporary reorganization of intrapartum maternity care during the coronavirus pandemic has put 4 options of childbirth: homebirth, alongside midwifery-led unit, freestanding midwifery-led unit, and obstetric unit. Freestanding mid-wife led delivery services are forwarded as viable options of childbirth by both NHS and RCOG guidance $[17,21]$. But this usually requires a response from an ambulance service, which may also currently be stretched. This means transfers from home to the hospital may not be sufficiently quick to ensure the safety of mother and baby [17].

\section{Post-natal care}

Modification of postnatal services is recommended with fewer visits and provision of care with telehealth. Telehealthcare even can extend to those patients who have undergone surgeries. Generally, earlier discharge of mothers with uncomplicated deliveries is recommended (immediate or less than $24 \mathrm{~h}$ in those after vaginal delivery and after $24 \mathrm{~h}$ in cesarean section [13].

In the presence of community-based health worker's homes, postnatal care provision is another option suggested by WHO [4]. The RCOG postnatal care guidance recommends for most women telephone or home visits 
may be preferable to community clinic visits to comply with social distancing. Face to face visiting is recommended for women with Known psycho-social vulnerabilities, operative birth, premature/low birth weight baby, and other medical or neonatal complications [11]. But ACOG advisory commentary suggests that phone call consultations and video conferencing with inspection of photos of wound site can be done in women who have undergone surgery [13].

\section{Contraception service}

\section{For women already on contraception}

Telemedicine and self-care family planning methods were recommended consistently. Self-care family planning methods include contraceptive pills, self-injectables, subcutaneous depo shots, condoms, vaginal rings, and fertility awareness methods [WHO, FIGO, RCOG, RCM, SOGC, RANZOG, IPPF, UNFPA, MSI, and FSRH] [3, 22-26].

There are consistent position statements that recommend combined hormonal contraception $(\mathrm{CHC})$ and progesterone-only pills (POP) users to continue 6-12 months without visits and rechecking body mass index (BMI) and blood pressure. Depot medroxyprogesterone acetate (DMPA) users can switch to available progesterone-only pills (POP) to avoid face to face contact $[3,22,27,28]$. For long term contraceptive user's options of extended use to avoid face to face contact is recommended. Limited evidence shows that the duration of the long-acting contraceptive effect is 2 years beyond the Food and Drug Administration (FDA)-approved duration [29]. Depending on that evidence many associations and organizations practice recommendations [FIGO, RCOG, RCM, SOGC, RANZOG, IPPF, UNFPA, MSI, and FSRH] advised delaying removal of implants and IUCD during the pandemic crisis unless a series of side effect happens or wants to get pregnant $[3,22,25,28,30,31]$.

\section{New contraception starters}

Telemedicine and self-care family planning with remote assessment and prescription of CHC, POP for 6-12 months, and self-injectable contraception were consistently recommended. However, administration of DMPA or insertion of implants or intrauterine devices to be considered where concerns about adherence, individual intolerance of oral contraceptives, or use of teratogens make longer-acting reversible contraception the only suitable option. Pre-procedure assessment and information-giving remotely to minimize face-to-face contact time (minimum contact service) with healthcare professionals were recommended [WHO, FIGO, RCOG, RCM, SOGC, RANZOG, IPPF, UNFPA, MSI, and FSRH]. Optimal use of contact points, such as expanding post-partum family planning with a special focus on long-acting reversible contraception was recommended [FIGO, RCOG, RCM, FSRH, MSI, and UNFPA].

\section{Emergency contraception (EC)}

Remote assessment of requirements and choice of EC. Oral emergency contraception remote prescription or provision without prescription or $\mathrm{Cu}$-IUD provision with minimum face to face contact is recommended [RCOG, RCM, FSRH, BSACP, FIGO].

\section{Safe abortion service}

All records (practice recommendations and position papers or commentaries) consistently recommend screening for COVID-19 symptoms from remote before face to face contact or during remote early medication abortion without face to face contact. There were several recommendations on no-touch/no-test early medication abortion protocol $[2,3,27,30,32]$. The no-touch protocol depicts pathways to minimize COVID-19 exposure to patients and staff by organizing early medical abortion services to be delivered via video or teleconferencing /telemedicine and delivery of a treatment package [2, 27, 30]. The treatment package includes mifepristone, misoprostol, ibuprofen, and self-care family planning. The no-touch/no-test protocol is self-medication abortion in early pregnancy without pre-procedure ultrasound and blood testing. The guideline also indicated that for women in self-isolation because of exposure to COVID19 no-touch early medication abortion can be arranged similarly at home. If face to face contact care is a must for COVID-19 exposed women, the guideline recommends that it should be booked when the isolation period is over unless the gestation is uncertain, and the delay may result in a woman not being able to access abortion in which face to face contact must be arranged with full personal protective measures [27]. There is no specific protocol recommended for second-trimester medication abortion (above 12 weeks), but professional association and organizations position papers consistently recommend the utilization of telemedicine for digital patient education and counseling to reduce waiting for periods and extent of face to face contact (minimal contact service) $[4,30,32,33]$.

For surgical abortion position papers and practice, recommendations focus on minimum contact procedures by remote digital patient education, counseling, and evaluation. The other focus practice recommendation is increasing safety during the procedure by limiting the number of people in the procedure room, appropriate use of personal protective equipment's and decontaminate area after the procedure as per the recommendation $[30,32,33]$. The practice recommendations also include surgical facemask and sanitizer or hand washing for women. Vacuum aspiration, dilatation, and evacuation 
or dilatation and curettage are not aerosol-generating procedures unless done by general anesthesia [34]. Therefore, these procedures don't require full personal protective equipment like N95, but abortion provides should screen all patients before the procedure and use standard precautions. Where possible and feasible it's also highlighted to perform the procedures under local anesthesia or intravenous sedation or spinal anesthesia to avoid the need for general anesthesia [27, 30, 32, 34]. It recommended consistently that follow-up visits are not required in all conditions and were needed to be done remotely by telemedicine.

\section{Gender-based violence (GBV)}

It is recommended that medical, legal, and policy mechanisms for victims of gender-based violence remain in place during the pandemic crisis. Access to clinical care (medical evaluation and management) for rape survivors is recommended to be maintained $24 / 7$ with necessary modifications in referral pathways to increase access [UNFPA, WHO, FIGO, RANZOG, RCOG, RCM, FSRH, and UN Women] [3, 4, 33, 35, 36].

\section{Assisted reproductive technology (ART)}

It recommended that assisted reproduction (including diagnostic procedures for infertility) shouldn't be started during the pandemics except in cases of urgent fertility preservation such as in oncology patients, the cryopreservation of gametes, embryos, or tissue can still be considered [ESHRE, BFS, FSA, HFEA, SASREG, and ASRM]. For those already on treatment it's recommended to freeze all for later embryo transfer [37-42].

\section{Discussion}

In this review, we attempted to locate documents in the form of guidelines, consensus statements, best practice statements, and standards of practice indicating directions on how reproductive health service during COVID-19 pandemics. We searched guideline databases, MEDLINE, EMBASE, and Google Scholar and the website of international professional associations and organizations working on sexual and reproductive health. Several international associations and organizations have declared service related to reproductive health, including contraception and safe abortion care as essential health service to continue during the COVID-19 pandemics [WHO, ACOG, RCOG, FIGO, RCM, SOGC, RANZCOG, SFP, NAF, IPPF, UNFPA, MSI, BSACP, and FSRH].

There were consistent consensus statements and recommendations that there should be access to routine SRH services like ANC, PNC, essential newborn care, breastfeeding support, contraception service, safe abortion care, and clinical management of rape survivors during the COVID-19 pandemics. This is very important to maintain service delivery and prevent indirect mortalities and morbidities from the pandemic as in the past Ebola virus outbreak in 2013-2016 in Western Africa. For example, according to an analysis of data from Sierra Leone's Health Management Information System, decreases in maternal and newborn care due to various reasons related to the Ebola outbreak contributed to an estimated 3600 maternal deaths, neonatal deaths, and stillbirth, a quantity that approaches the number of deaths directly caused by the Ebola virus in the country [9]. Evidence also shows that the number of antenatal care visits and facility deliveries after the Ebola epidemic in Guinea had not recovered to prior levels after 6 months, suggesting the possibility of epidemic sustained effects on the different reproductive health care [43]. Therefore, the lessons from past outbreaks like Ebola exemplify the necessity of implementing evidencebased guidelines and recommendations to maintain the continuation of reproductive services during the COVID-19 pandemic. The practice recommendations identified by the current review focus on minimizing patient and staff exposure to COVID-19 by utilizing telemedicine or digital health and includes the following: Pre-triage (screening) of all clients visiting a health facility for COVID-19, modification of antenatal care provision from face-to-face to telehealth (voice or video calls), if possible, a one-stop clinic service provision with clinical examination and lab tests were done on the same visit, instituting targeted obstetric referral and counter-referral criteria, re-organization of intrapartum care and modification of postnatal services with earlier discharge, community-based (mid-wife led) or home births with functional back-up referral systems and modification (reorganization) of obstetrical referral pathways, no-touch/no-taste early medication abortion or minimum contact safe abortion care and self-serving family planning.

The utilization of digital health is well recognized in increasing access to service. The WHO recommends selfmanagement of different conditions including abortion less than 12 weeks provided that women had easy access to information [44]. However, the utilization of telemedicine might be difficult in many low- and middle-income countries in which awareness and utilization of digital health are very low. This might exacerbate the already existing health inequity. To overcome such gaps awareness creation campaigns and utilization of community health workers are very imperative.

For women already on combined hormonal contraception $(\mathrm{CHC})$ and progesterone-only pills (POP), it's recommended to continue 6-12 months without rechecking body mass index (BMI) and blood pressure during the pandemics to reduce exposure to COVID-19. Furthermore, it is recommended to use options of extended use 
of long-term contraceptive methods to avoid face to face contact during the pandemics. Additionally, during COVID-19 pandemics every stakeholder should make sure medical, legal, and policy mechanisms for victims of gender-based violence are in place. However, many recommend not to start a new assisted reproduction cycle during the pandemic except for fertility preservation and to freeze all embryos for those who were already on treatment.

\section{Strengths and limitations}

The review located and summarized contemporary international and national guidelines and recommendations on reproductive health service organization and service delivery during COVID-19 pandemics. This is the very timely and important review that guides service delivery amid COVID-19. The review will also be used as a bench mark to frame the reproductive service delivery approach in cases of any future pandemic or epidemic. We searched professional associations and organization's websites, guideline databases, and databases to make the search as comprehensive as possible. The selection of professional associations and organization's websites was based on the author's consensus and recommendation by reproductive health experts which might have introduced selection bias. Our review included only documents published in English which might result in missing relevant non-English publications. Additionally, most of the documents included didn't pass through a rigorous guideline development process because of the nature of the pandemic. Furthermore, we did not perform a formal critical appraisal of individual records for this systematic scoping review. The review included records published until April 30/ 2020 which might result in missing records that are published after that. There is geographical variation in the records included in this review which might be because of the timing of the spread of COVID-19 to different continents. Hence, we plan to update the review within 6 months of publication to include missed records and generate more comprehensive evidence.

\section{Conclusions}

\section{Implications for practice}

There were consistent consensus statements and recommendations that there should be access to sexual and reproductive health services during the COVID-19 pandemics with the concerted effort of service reorganization. The practice recommendations focus on innovative ways of service provision to minimize patient and staff exposure to COVID-19 as well as alleviate the burden on the health care system. These include utilizing telemedicine and community/home-based care or self-care.

\section{Implications for research}

Most of the documents that are included in this review didn't pass through a rigorous guideline development process because of the nature of the pandemic. New evidence is evolving with time as the duration of the pandemic extends. Hence, we recommend primary studies and systematic reviews to generate evidence on the impact of new practices, map and document best practice implementations.

\section{Supplementary Information}

The online version contains supplementary material available at https://doi. org/10.1186/s12889-021-10346-2

Additional file 1. Data extraction tool ANC, labour and delivery, and postnatal care.

Additional file 2. Data extraction tool safe abortion, contraception, GBV, and ART service.

\section{Appendix 1}

\section{Search Strategy}

We searched website of the following associations and organizations: World Health Organization (WHO), America College of Obstetrics and Gynecology (ACOG), Royal College of Obstetrics and Gynecology (RCOG), International Confederation of Midwives (ICM), Royal College of Midwives (RCM),International Society of Ultrasound in Obstetrics and Gynecology (ISUOG),International Federation of Obstetrics and Gynecology (FIGO),Society of Maternal and Fetal Medicine (SMFM),Society of Obstetrics and Gynecology of Canada (SOGC),RANZCOG (The Royal Australian and New Zealand College of Obstetricians and Gynecologists), National Health Service (NHS), UNICEF (United Nations International Children's Emergency Fund), Faculty of Sexual and Reproductive Healthcare (FSRH), British Society of Abortion Care Providers (BSACP), National Abortion Federation (NAF), Society of Family Planning (SFP),United Nations Population Fund (UNFPA), International Planned Parenthood Federation

Table 2 Search Strategy 1. The search was conducted on April 18, 2020, MEDLINE (Ovid).

\begin{tabular}{lll}
\hline Number & Search Query & Result. \\
\hline 1 & $\begin{array}{l}\text { COVID-19 [tw] OR Sars cov-2[tw] OR Pandemics [tw] OR epidemics [tw] AND maternal care [tw] OR reproductive service [tw] OR } \\
\text { antenatal care [tw] OR labour [tw] OR delivery [tw] OR abortion [tw] OR contraception [tw] OR family planning [tw] }\end{array}$ \\
2 & Limit 1 to English AND Human AND 1 year. & 0931 \\
2 & 400 \\
\hline
\end{tabular}


(IPPF), Marie stopes International (MSI), European Society of Human Reproduction and Embryology (ESHRE), American Society for Reproductive Medicine (ASRM),Human Fertilization and Embryology Authority (HFEA),British Fertility Society (BFS), Chinese Obstetricians and Gynecologists Association (COGA), The fertility Society of Australia (FSA), African Federation of Obstetricians and Gynaecologist (AFOG), Southern African Society of Reproductive Medicine and Gynecological Endoscopy (SASREG) and the Asia \& Oceania Federation of Obstetrics \& Gynecology (AOFOG). The guideline databases searched were: Turning Research into Practice (TRIP) database, Guideline International (GIN) library, National Guideline Clearinghouse (NGC), and National Institute for Health and Clinical Excellence (NICE).

\begin{abstract}
Abbreviations
SRH: Sexual and Reproductive Health; ANC: Antenatal Care; PNC: Postnatal care; WHO: World Health Organization; ACOG: America College of Obstetrics and Gynecology; RCOG: Royal College of Obstetrics and Gynecology; ICM: International Confederation of Midwives; RCM: Royal College of Midwives; ISUOG: International Society of Ultrasound in Obstetrics and Gynecology; FIGO: International Federation of Obstetrics and Gynecology; SMFM: Society of Maternal and Fetal Medicine; SOGC: Society of Obstetrics and Gynecology of Canada; RANZCOG: The Royal Australian and New Zealand College of Obstetricians and Gynecologists; NHS: National Health Service; UNICEF: United Nations International Children's Emergency Fund; FSRH: Faculty of Sexual and Reproductive Healthcare; BSACP: British Society of Abortion Care Providers; NAF: National Abortion Federation; SFP: Society of Family Planning: UNFPA: United Nations Population Fund; IPPF: International Planned Parenthood Federation; MSI: Marie stopes International (MSI); ESHRE: European Society of Human Reproduction and Embryology; ASRM: American Society for Reproductive Medicine; HFEA: Human Fertilization and Embryology Authority; BFS: British Fertility Society; COGA: Chinese Obstetricians and Gynecologists Association; FSA: The fertility Society of Australia (FSA); AFOG: African Federation of Obstetricians and Gynecologist; SASREG: Southern African Society of Reproductive Medicine and Gynecological Endoscopy; AOFOG: Asia \& Oceania Federation of Obstetrics \& Gynecology; TRIP: Turning Research into Practice; GIN: Guideline International; NGC: National Guideline Clearinghouse; NICE: National Institute for Health and Clinical Excellence; MSI : Marie Stopes International
\end{abstract}

\section{Acknowledgments}

Not applicable.

\section{Authors' contributions}

All authors have read and approved the manuscript and ensured their contribution. Conceptualization: LBT, WGJ. Data curation: LBT, WGJ. Formal analysis: LBT, WGJ. Funding acquisition: NA. Investigation: LBT, WGJ, GTF. Methodology: LBT, WGJ, GTF. Project administration: LBT, WGJ, GTF. Resources: LBT, WGJ, GTF. Software: LBT, WGJ, GTF. Supervision: LBT, WGJ, GTF. Validation: LBT, WGJ, GTF

\section{Funding}

This scoping review project did not get any funding support from any organization.

\section{Availability of data and materials}

All the data set used were included in the manuscript and supplementary materials.

Ethics approval and consent to participate Not applicable.
Consent for publication

Not applicable.

\section{Competing interests}

The authors declare no competing interests in this review.

\section{Author details}

'Department of Obstetrics and Gynecology, Saint Paul's Hospital Millennium Medical College, Addis Ababa, Ethiopia. ${ }^{2}$ Department of Health, Behaviour, and Society, Jimma University, Jimma, Ethiopia.

Received: 4 May 2020 Accepted: 27 January 2021

Published online: 03 February 2021

References

1. Adhikari SP, Meng S, Wu Y-J, Mao Y-P, Ye R-X, Wang Q-Z, et al. Epidemiology, causes, clinical manifestation and diagnosis, prevention and control of coronavirus disease (COVID-19) during the early outbreak period: a scoping review. Infect Dis Poverty. 2020;9(1):1-12.

2. No Touch Medication Abortion Protocol [Available from https://www. reproductiveaccess.org/resource/no-touch-mab-protocol/.

3. RANZCOG - COVID-19: Access to reproductive health services [Available from https://ranzcog.edu.au/news/covid-19-access-to-reproductive-healthservices.

4. World Health Organization. COVID-19: operational guidance for maintaining essential health services during an outbreak: interim quidance. Available at https://apps.who.int/iris/handle/10665/331561. Accessed 25 Mar 2020.

5. World Health Organization. Clinical management of severe acute respiratory infection (SARI) when COVID-19 disease is suspected: interim guidance. Available at https://www.who.int/docs/defaultsource/coronaviruse/dinicalmanagement-of-novel-cov.pdf. Accessed 13 Mar 2020

6. Huynh G, Nguyen MQ, Tran TT, Nguyen VT, Nguyen TV, Do THT, et al. Knowledge, attitude, and practices regarding COVID-19 among chronic illness patients at outpatient departments in Ho Chi Minh City, Vietnam. Risk Manage Healthc Policy. 2020;13:1571.

7. Afzal MS, Khan A, Qureshi UUR, Saleem S, Saqib MAN, Shabbir RMK, et al. Community-based assessment of knowledge, attitude, practices and risk factors regarding COVID-19 among Pakistanis residents during a recent outbreak: a cross-sectional survey. J Community Health. 2020:1-11.

8. Marie Stopes International (MSI) response to the COVID-19 crisis \%U https:// www.mariestopes.org/covid-19.

9. Sochas L, Channon AA, Nam S. Counting indirect crisis-related deaths in the context of a low-resilience health system: the case of maternal and neonatal health during the Ebola epidemic in Sierra Leone. Health Policy Plan. 2017;32(suppl_3):iii32-i9.

10. The scoping review framework - JBI Manual for Evidence Synthesis - JBI GLOBAL WIKI [Available from https://wiki.jbi.global/display/MANUAL/11.1.3+ The+scoping+review+framework

11. RCOG. Guidance for antenatal screening and ultrasound in pregnancy in the evolving coronavirus (COVID-19) pandemic. Version 1: Published Monday 23 March 2020. Available at: https://www.rcog.org.uk/en/ guidelines-research-services/guidelines/coronaviruspregnancy/

12. Boelig RC, Manuck T, Oliver EA, Di Mascio D, Saccone G, Bellussi F, Berghella V. Labor and delivery guidance for COVID-19. Am J Obstet Gynecol MFM. 2020;2(2):100110. https://doi.org/10.1016/j.ajogmf.2020.100110. Epub 2020 Mar 25. PMID: 32518901; PMCID: PMC7270486.

13. Rasmussen, Sonja A, and Denise J Jamieson. "Coronavirus Disease 2019 (COVID-19) and Pregnancy: Responding to a Rapidly Evolving Situation." Obstetrics and gynecology. 2020;135(5):999-1002. https://doi.org/10.1097/ AOG.0000000000003873.

14. The Society for Maternal-Fetal Medicine (SMFM), Dotters-Latz S, Hughes B. Coronavirus (COVID-19) and Pregnancy: What Maternal-Fetal Medicine Subspecialists need to know. https://s3.amazonaws.com/cdn.smfm.org/ media/2267/COVID19-_updated_3-17-20_PDF.pdf.

15. FIGO. Global interim guidance on coronavirus disease 2019 (COVID-19) during pregnancy and puerperium from FIGO and allied partners: Information for healthcare professionals. DOI: https://doi.org/10.1002/JJGO 13156.

16. RCM/RCOG. Guidance for antenatal and postnatal services during the evolving Coronavirus (COVID-19) pandemic. Available at: https://www.rcog org.uk/en/guidelines-research-services/guidelines/coronaviruspregnancy/ 
17. NHS. A clinical guide for the temporary re-organization of intrapartum maternity care during the coronavirus pandemic. April 9. Version 1. available at https://www.england.nhs.uk/coronavirus/wp-content/uploads/sites/52/2 020/04/C0241-specialty-guide-intrapartum-maternity-care-9-april-2020.pdf.

18. RCOG. Coronavirus (COVID-19) Infection in Pregnancy. Published Monday 23 March 2020. Available at: https://www.rcog.org.uk/en/guidelines-researchservices/guidelines/coronaviruspregnancy/

19. RCM. Optimizing maternity services and maternal and newborn outcomes in a pandemic. A rapid analytic scoping review. 2020. https://www.rcm.org.uk/ media/3869/rapid-review-optimising-maternity-services-for-rcm-v4-8-april.pdf.

20. ICM. Women's Rights in Childbirth Must be Upheld During the Coronavirus Pandemic: ICM OFFICIAL STATEMENT; 2020. www.internationalmidwives.org

21. RCOG. Guidance for provision of midwife-led settings and home birth in the evolving coronavirus (COVID-19) pandemic. Information for healthcare professionals Version 1: Published April 9, 2020. Available at: https://www. rcog.org.uk/en/guidelines-research-services/guidelines/ coronaviruspregnancy.

22. Reproductive access project. Contraception in the Time of COVID-19 [Available from https:/www.reproductiveaccess.org/resource/contraception-covid/.

23. FSRH CEU: information to support the management of individuals requesting to discontinue contraception to plan pregnancy during the Covid-19 outbreak (26 March 2020) - Faculty of Sexual and Reproductive Healthcare [Available from https://www.fsrh.org/documents/fsrh-ceuinformation-to-support-management-of-individuals/.

24. World Health Organization (WHO). Contraception/ family planning, and COVID-19\%U https://www.who.int/news-room/q-a-detail/contraceptionfamily-planning-and-covid-19.

25. FIGO. COVID-19 Contraception and Family Planning. https://www.figo.org/ covid-19-contraception-and-family-planning [Available from https://www. rcog.org.uk/en/guidelines-research-services/guidelines/coronaviruspregnancy/covid-19-virus-infection-and-pregnancy/.

26. Sexual and Reproductive Health and Rights: Modern Contraceptives and Other Medical Supply Needs, Including for COVID-19 Prevention, Protection and Response [Available from: /resources/sexual-and-reproductive-healthand-rights-modern-contraceptives-and-other-medical-supply.

27. Royal College of Obstetricians and Gynaecologists, Faculty of Sexual and Reproductive Healthcare and the British Society and Abortion Care Providers. Coronavirus (COVID-19) infection and abortion care \%U https:// www.rcog.org.uk/en/guidelines-research-services/guidelines/coronavirusabortion. Royal College of Obstetricians \& Gynaecologists.

28. Faculty of Sexual \& Reproductive Healthcare. FSRH CEU clinical advice to support the provision of effective contraception during the COVID-19 outbreak. 2020. Available: https://www.fsrh.org/documents/fsrh-ceu-clinicaladvice-to-support-provision-of-effective/

29. McNicholas C, Swor E, Wan L, Peipert JF. Prolonged use of the etonogestrel implant and levonorgestrel intrauterine device: 2 years beyond Food and Drug Administration-approved duration. Am J Obstet Gynecol. 2017;216(6): 586.e1-6.

30. FSRH, RCOG, RCM, and BSACP launch joint guidance on COVID-19 and abortion care - Faculty of Sexual and Reproductive Healthcare \%U https:// www.fsrh.org/news/fsrh-rcog-and-bsacp-guidance-on-covid-19-abortion.

31. FSRH, RCOG \& RCM statement provision of postpartum contraception during Covid-19 - Faculty of Sexual and Reproductive Healthcare [Available from https://www.fsrh.org/documents/fsrh-rcog-rcm-statement-postpartumcontraception-covid19/.

32. National Abortion Federation. Abortion \& COVID-19 [Available from: https:// prochoice.org/abortion-covid-19/.

33. FSRH Position: Essential SRH Services during COVID-19 March 2020 - Faculty of Sexual and Reproductive Healthcare \%U https://www.fsrh.org/ documents/fsrh-position-essential-srh-services-during-covid-19-march-2020.

34. American College of Surgeons. COVID-19: Elective Case Triage Guidelines for Surgical Care,March 24,2020 [Available from: https://www.facs.org/covid-19/ clinical-guidance/elective-case.

35. UNFPA. COVID-19: A Gender Lens [Available from: /resources/covid-19gender-lens

36. UN Women. COVID-19 and ending violence against women and girls Digital library: Publications [Available from https://www.unwomen.org/en/ digital-library/publications/2020/04/issue-brief-covid-19-and-endingviolence-against-women-and-girls.

37. Fertility Society of Australia » COVID-19 Information [Available from https:// www.fertilitysociety.com.au/home/fsa-statement-covid-19/.
38. ESHRE News [Available from https://www.eshre.eu/Press-Room/ESHRENews\#COVID19_April2.

39. Guidance for the care of fertility patients during the Coronavirus COVID-19 Pandemic » British Fertility Society [Available from https://www. britishfertilitysociety.org.uk/2020/03/18/guidance-for-the-care-of-fertilitypatients-during-the-coronavirus-covid-19-pandemic/.

40. Coronavirus (COVID-19) guidance for professionals | Human Fertilisation and Embryology Authority [Available from https://www.hfea.gov.uk/treatments/ covid-19-and-fertility-treatment/coronavirus-covid-19-guidance-forprofessionals/.

41. Patient Management and Clinical Recommendations During The Coronavirus (COVID-19) Pandemic - updated March 30, 2020, | ASRM [Available from https://www.asrm.org/Patient-Mgmt-COVID-19.

42. Guidance on Fertility care and surgery during COVID-19 | 19 March 2020 [Available from https://sasreg.co.za/guidance-on-fertility-care-and-surgeryduring-covid-19-19-march-2020/.

43. Camara BS, Delamou A, Diro E, Béavogui AH, El Ayadi AM, Sidibé S, et al. Effect of the 2014/2015 Ebola outbreak on reproductive health services in a rural district of Guinea: an ecological study. Trans R Soc Trop Med Hyg. 2017:111(1):22-9.

44. Health worker roles in providing safe abortion care and post-abortion contraception available at https://apps.who.int/iris/bitstream/handle/1 0665/181041/9789241549264_eng.pdf;jsessionid=ACEFC080B3B4467165B25 DF15720AD24? sequence=1. World Health O, editor. Geneva, Switzerland: World Health Organization.

\section{Publisher's Note}

Springer Nature remains neutral with regard to jurisdictional claims in published maps and institutional affiliations.
Ready to submit your research? Choose BMC and benefit from:

- fast, convenient online submission

- thorough peer review by experienced researchers in your field

- rapid publication on acceptance

- support for research data, including large and complex data types

- gold Open Access which fosters wider collaboration and increased citations

- maximum visibility for your research: over $100 \mathrm{M}$ website views per year

At BMC, research is always in progress.

Learn more biomedcentral.com/submissions 